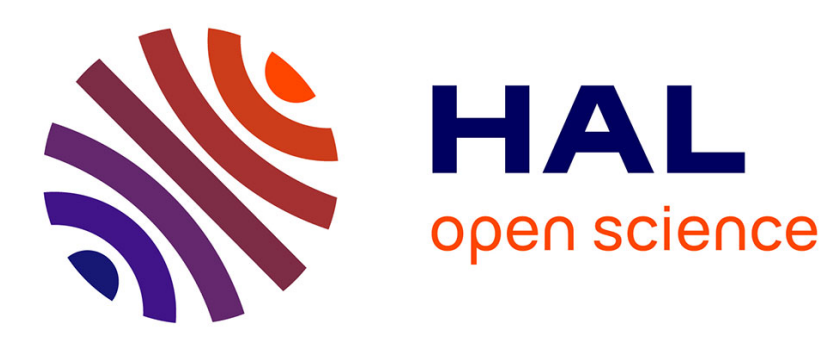

\title{
Skill of Sahel rainfall variability in four atmospheric GCMs forced by prescribed SST
}

\author{
Vincent Moron, N. Philippon, B. Fontaine
}

\section{To cite this version:}

Vincent Moron, N. Philippon, B. Fontaine. Skill of Sahel rainfall variability in four atmospheric GCMs forced by prescribed SST. Geophysical Research Letters, 2003, 30 (23), pp.n/a-n/a. 10.1029/2003GL018006 . hal-02895214

\section{HAL Id: hal-02895214 \\ https://hal.science/hal-02895214}

Submitted on 28 Jan 2021

HAL is a multi-disciplinary open access archive for the deposit and dissemination of scientific research documents, whether they are published or not. The documents may come from teaching and research institutions in France or abroad, or from public or private research centers.
L'archive ouverte pluridisciplinaire HAL, est destinée au dépôt et à la diffusion de documents scientifiques de niveau recherche, publiés ou non, émanant des établissements d'enseignement et de recherche français ou étrangers, des laboratoires publics ou privés. 


\title{
Skill of Sahel rainfall variability in four atmospheric GCMs forced by prescribed SST
}

\author{
V. Moron, ${ }^{1,2}$ N. Philippon, ${ }^{3}$ and B. Fontaine ${ }^{3}$ \\ Received 19 June 2003; revised 3 November 2003; accepted 10 November 2003; published 12 December 2003.
}

[1] The inter-annual and long-term variability of JulySeptember regional rainfall over the central and western Sahel $\left(16^{\circ} \mathrm{W}-20^{\circ} \mathrm{E} ; 11.25^{\circ}-18.75^{\circ} \mathrm{N}\right)$ is evaluated using 21 runs from four atmospheric general circulation models (AGCMs) integrated from 1948. The skill is stronger at decadal time scales: each AGCM simulates quite successfully the rainfall decrease from the wet 1950-60s toward the dry 1970-90s although its amplitude is lower than observed. At inter-annual time scales, the skill is smaller and decreases over time between the 1950-70s and the recent dry period; all AGCMs have a close to zero skill around the 1980s. This is not linked to a reduced AGCM sensivity to global SST but to their failure to reproduce the observed SST-rainfall teleconnection changes, in particular the weakening (strengthening) linear relationship with the equatorial and southern Atlantic (equatorial Pacific). INDEX TERMS: 3309 Meteorology and Atmospheric Dynamics: Climatology (1620); 3337 Meteorology and Atmospheric Dynamics: Numerical modeling and data assimilation; 3354 Meteorology and Atmospheric Dynamics: Precipitation (1854); 3374 Meteorology and Atmospheric Dynamics: Tropical meteorology. Citation: Moron, V., N. Philippon, and B. Fontaine, Skill of Sahel rainfall variability in four atmospheric GCMs forced by prescribed SST, Geophys. Res. Lett., 30(23), 2221, doi:10.1029/2003GL018006, 2003.

\section{Introduction}

[2] Long-term observed rainfall variations over Sahel exhibit significant changes from wet conditions in the 1950-60s to drier ones in the 1970-90s. These interdecadal fluctuations represent one of the strongest climatic signals in the 20th century [AMMA, 2002]: the abnormally dry conditions have been associated with warmer than normal sea surface temperatures (SST) in the southern Atlantic, the southern and equatorial Pacific (El Niño conditions) and the Indian ocean, and colder than normal SSTs in the northern Atlantic and the northern Pacific [e.g., Folland et al., 1986; Fontaine and Janicot, 1996; Rowell et al., 1995; Ward, 1998]. These relationships depend strongly on the frequencies considered since teleconnections between Sahelian seasonal rainfall and SST at low frequency (LF) time scales differ from those at high-frequency (HF) [e.g., Ward, 1998]. Moreover, at HF time scales, relationships between Sahelian seasonal rainfall and

\footnotetext{
${ }^{1}$ UFR des Sciences Géographiques et de l'Aménagement, Aix en Provence, France.

${ }^{2}$ CEREGE, UMR6635, Europôle méditerranéen de l'Arbois, France.

${ }^{3}$ CRC, UMR 5080, Faculté Sciences Gabriel, Dijon, France.
}

Tropical Pacific and southern and equatorial Atlantic are unstable [Janicot et al., 1996, 2001].

[3] It is clear that many AGCMs forced by prescribed SST have difficulty in reproducing these teleconnections fluctuations, especially at HF time scales [Sperber and Palmer, 1996; Sud and Lau, 1996]. This is partly due to the fact that the range of physical processes and scales involved in rainfall cannot be fully resolved in any AGCM and must be parameterized; accurate simulation of rainfall represents a great challenge for AGCMs.

[4] The aim of this study is to investigate the skill (i.e., similarity between simulations and observations) and reproducibility (i.e., similarity amongst the runs) of a seasonal Sahelian rainfall index (SRI) in 4 AGCMs (ARPEGE, GISS, ECHAM 3 and ECHAM 4) forced by the same prescribed SSTs. These AGCMs capture the temporal variability of a regional monsoon wind index reasonably [Fontaine et al., 1995]. An analysis of the variations of skill at HF time scales and of the teleconnections between SRI and some SST indices is also performed. This letter is divided into six sections: section 2 briefly describes the data and methods, sections 3, 4 and 5 present respectively the mean skill, its time evolution and the reproducibility, and the relationships with 4 SST indices. Section 6 provides concluding remarks.

\section{Data and Methods}

[5] The AGCMs used in this study have been already presented in Moron et al. [2001] for ECHAM 3 and 4, Cassou and Terray [2001] for ARPEGE and Hansen et al. [2002] for GISS and only a brief summary is given here (Table 1).

[6] The runs are forced with observed SST and ice coverage from the data set provided by the Hadley centre. All runs differ only by their initial conditions. The soil hydrology uses a "bucket scheme" (i.e., a single soil layer with constant moisture capacity) in ECHAM 3 and ECHAM 4 and a more physically-based approach to predict soil moisture for ARPEGE and GISS. The highest rainfall associated with the northernmost location of the InterTropical Convergence Zone are located slightly too far north in these AGCMs, but this shift does not exceed $2^{\circ}$ (not shown). There is also a weak dry bias, except for ARPEGE.

[7] SRI is defined as the standardized mean of the standardized anomalies inside the Sahelian box $\left(16^{\circ} \mathrm{W}-\right.$ $\left.20^{\circ} \mathrm{E} ; 11.25^{\circ} \mathrm{N}-18.75^{\circ} \mathrm{N}\right)$, matching the usual definition of central and western Sahel [e.g., Rowell et al., 1995; Fontaine and Janicot, 1996; Ward, 1998; Philippon and Fontaine, 1999]. Observations are taken from the Climatic Research Unit data set [Hulme, 1992]. For each AGCM, SRI is computed for each run and then averaged. The time series are filtered with a butterworth digital filter which divides the variance into HF and LF parts. The cut-off is at 
Table 1. Main Characteristics of the 4 AGCMs Used

\begin{tabular}{lcccc}
\hline \multicolumn{1}{c}{ AGCM } & $\begin{array}{c}\text { Horizontal } \\
\text { resolution }\end{array}$ & $\begin{array}{c}\text { Vertical } \\
\text { resolution }\end{array}$ & $\begin{array}{c}\text { Number of } \\
\text { runs available }\end{array}$ & $\begin{array}{c}\text { Period } \\
\text { available }\end{array}$ \\
\hline ECHAM 3 & T21 & 19 & 5 & $1950-1994$ \\
ECHAM 4 & T30 & 19 & 3 & $1961-1994$ \\
ARPEGE & T63 & 31 & 8 & $1948-1997$ \\
GISS & $4^{\circ}$ (lat) $\times 5^{\circ}$ (lon) & 12 & 5 & $1951-1998$ \\
\hline
\end{tabular}

8 years as in Ward [1998]. Considering other cut-off values (such as 10 years) does not change the final results. Linear correlations are tested with the "random-phase" test [Janicot et al., 1996, 2001; Ebisuzaki, 1997]. For each pair of time series to be correlated, 1000 random time series having the same power spectrum as the original one but random phases are correlated and the linear correlations are ordered in ascending order. The upper $10 \%$ tail gives the one-tailed $10 \%$ level of significance with the alternative hypothesis that the correlation is positive. When running correlations are used, the procedure is the same, except that running correlations are computed on the random time series. Reproducibility is estimated with the method of Rowell [Rowell et al., 1998]. The full variance of an ensemble of runs of a given AGCM is separated into an internal and an external (= "SST-forced") part. This procedure is also used to estimate the similarity between the ensemble mean of each AGCM.

\section{HF and LF AGCM Skills}

[8] Table 2 displays correlations between observed and simulated SRI and Figure 1 presents the respective time series together with their LF and HF components. The observed SRI (Figure 1a) exhibits the classical behaviour already analysed by numerous authors [e.g., Folland et al., 1986; Ward, 1998; Philippon and Fontaine, 1999] and characterized by an opposition between the anomalously wet 1950-60s and dry 1970-90s. AGCMs quite accurately reproduce the decreasing trend (Table 2, "R-LF"). Note also (Figure $1 \mathrm{~b}$ ) that the simulated LF component is consistent amongst the AGCMs until 1975-1977, but quite different afterwards; the AGCMs do not simulate accurately the two driest phases in 1972-73 and 1982-84. Regarding the HF variability (Table 2, "R-HF"), the simulations are clearly not consistent with the observations, particularly for ECHAM 3 and 4.

\section{Time Evolution of HF Skill and Reproducibility}

[9] Figure 2a displays the temporal evolution of HF skill estimated from running 20-year periods (running windows

Table 2. Correlation Coefficients Between Observed and Simulated SRI for Non-Filtered (2nd Column), LF (3rd Column) and HF (4th Column) Time Series

\begin{tabular}{lcccc}
\hline & Period & $\mathrm{R}($ all $)$ & $\mathrm{R}-\mathrm{LF}$ & $\mathrm{R}-\mathrm{HF}$ \\
\hline ARPEGE 3 & $1948-1997$ & $0.59^{* * *}$ & $0.73^{*}$ & $0.34^{* *}$ \\
ECHAM 4 & $1961-1994$ & 0.10 & 0.47 & -0.06 \\
ECHAM 3 & $1950-1994$ & $0.57^{* * *}$ & $0.75^{*}$ & 0.22 \\
GISS 2000 & $1951-1998$ & $0.41^{* * *}$ & $0.75^{* * *}$ & $0.29 *$ \\
\hline
\end{tabular}

One, two and three stars indicate correlations significant at the $0.1,0.05$ and 0.01 one-sided levels respectively.
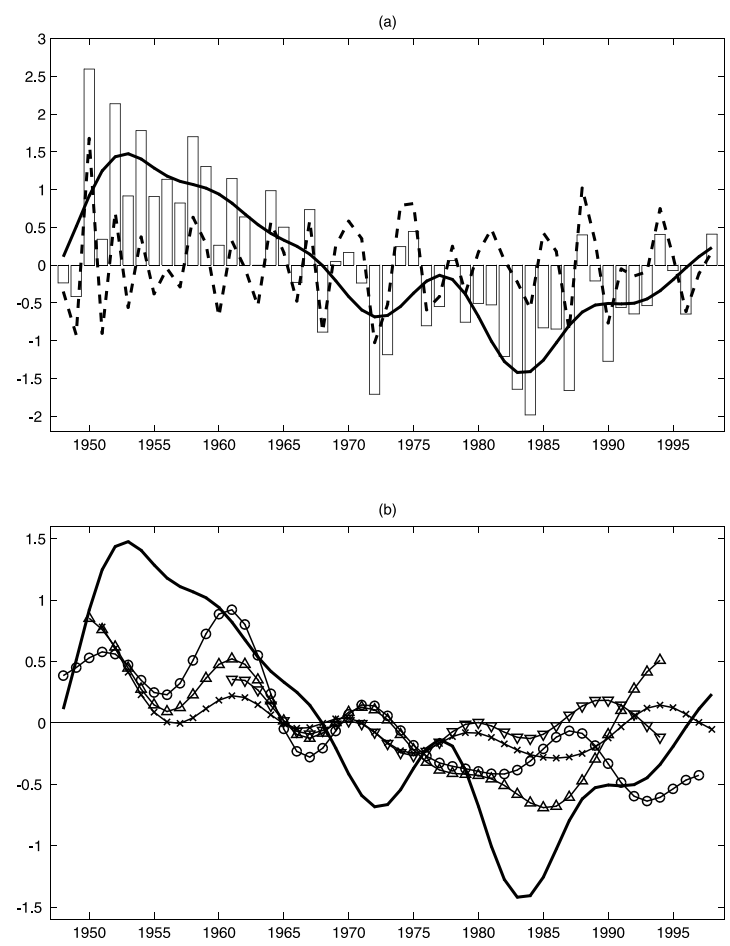

Figure 1. (a) Normalized observed SRI (bar) with its lowfrequency $(>8$ years) and high frequency $(<8$ years $)$ components superimposed as a full thick line and a dashed thick line respectively; (b) low-frequency ( $>8$ years) of observed (thick line) and simulated (thin line + circle: ARPEGE; upper triangle: ECHAM 3; lower triangle: ECHAM 4; cross: GISS) SRI.

from 15 to 25 years have been tested and found to yield similar results). The time evolution of correlations between the observed and simulated SRI is quite consistent amongst the AGCMs, with the skill strongly decreasing during the dry period. This is particularly clear for ARPEGE (circles in Figure 2a) which shows the highest correlations: skill ranges from moderate to strong until 1968-87 $(\mathrm{r}=$ $0.45-0.60)$ but decreases toward zero afterwards. The correlations for ECHAM 4 (lower triangle in Figure 2a) are never significant at the one-sided 0.1 level. Thus, HF SRI variability is better simulated during the wet period than during the driest period around the $80 \mathrm{~s}$. This is consistent with results of the first AMIP experiment [Sperber and Palmer, 1996; Sud and Lau, 1996] and may be related, to first order, to a decrease of the SST-forced variance.

[10] The mean values of SST-forced variance range from $21.5 \%$ (ECHAM 3) to 30\% (ARPEGE) indicating that at least $70 \%$ of the HF variability of SRI remains unpredictable from such AGCM integrations. This amount of internal variance limits the highest attainable skill [Rowell et al., 1995; Rowell, 1998]. The temporal evolution of SST-forced variance is quite noisy amongst the AGCMs; additionally, no systematic decrease of this SST-forced variance is observed during the driest period (Figure 2b) except for GISS (values range from $35-45 \%$ until $1969-88$ to $14-30 \%$ afterwards). The part of common variance (Figure $2 b$, thick lines) in the 4-members ensemble mean (or 3-members for 1951-1994) indicates the internal consistency between the AGCMs. 

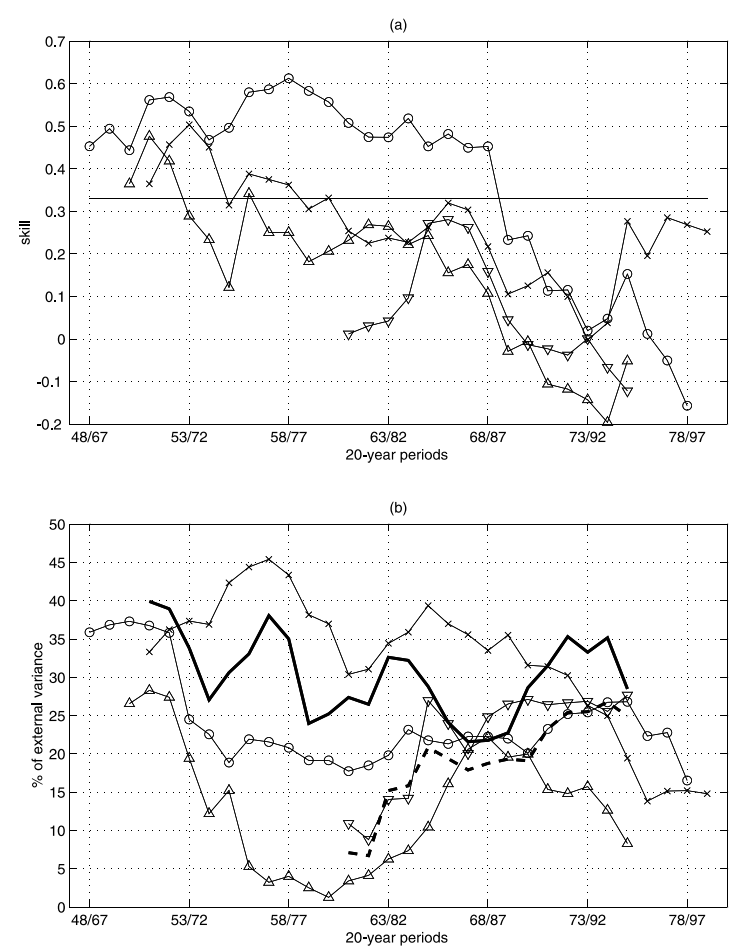

Figure 2. (a) Running correlations on 20-year overlapping periods between observed and simulated (thin line + circle: ARPEGE; upper triangle: ECHAM 3; lower triangle: ECHAM 4; cross: GISS) SRI. The straight line indicates the one-sided 0.1 level of significance; (b) SST-forced variance on 20-year overlapping periods for simulated (line + circle: 8 runs from ARPEGE; upper triangle: 5 runs from ECHAM 3; lower triangle: 3 runs from ECHAM 4; cross: 5 runs from GISS) SRI. The thick full (dashed) line is the common variance estimated from the mean score for GISS, ECHAM3 and ARPEGE (GISS, ECHAM3, ECHAM4 and ARPEGE).

Values range from $30 \%$ with 3 AGCMs (Figure 2b, thick full line) to $10 \%-25 \%$ with 4 AGCMs (Figure $2 \mathrm{~b}$, thick dashed line) but there is no decrease over time in contrast to skill. In other words, the observed skill decrease over the recent period seems unrelated to the decrease of SST-forced variance within a given ACGM ensemble or between AGCMs, but could be linked to (i) changes in the SST-SRI linear connections which are not (or only partly) reproduced by AGCMs, and/or (ii) an enhanced impact of land surface conditions on SRI variability during the dry period. The first point is further investigated in the next section.

\section{SST-SRI Linear Relationships and Their Evolution}

[11] The simulation of the SRI-SST teleconnections at HF timescales is studied with 4 SST subequatorial indices (NINO: $180^{\circ}-270^{\circ} \mathrm{E} 5^{\circ} \mathrm{N}-5^{\circ} \mathrm{S}$; EAT: $30^{\circ} \mathrm{W}-15^{\circ} \mathrm{E} ; 10^{\circ} \mathrm{S}-$ $5^{\circ} \mathrm{N}$; IND $40^{\circ}-60^{\circ} \mathrm{E} ; 5^{\circ} \mathrm{S}-10^{\circ} \mathrm{N}$; and WPAC $120^{\circ}-160^{\circ} \mathrm{E}$; $10^{\circ} \mathrm{S}-5^{\circ} \mathrm{N}$ ). Correlation values (Table 3 ) indicate that AGCMs do not simulate accurately the linear relationship between SST and SRI at this timescales; ARPEGE is the most skillful with correlations that agree in sign with the
Table 3. Correlation Coefficients Between Observed and Simulated SRI and 4 SST Indices at High-Frequency Timescales

\begin{tabular}{lccccc}
\hline & OBS- & ARPEGE- & ECHAM4- & ECHAM3- & GISS- \\
& HF & HF & HF & HF & HF \\
\hline NINO-HF & $-0.5^{* * *}$ & $-0.25^{*}$ & $0.56^{* * *}$ & -0.07 & -0.08 \\
EAT-HF & $-0.38^{* *}$ & -0.14 & $-0.39^{*}$ & $-0.39^{*}$ & $-0.46^{* * *}$ \\
IND-HF & $-0.47^{* * *}$ & -0.19 & 0.24 & -0.07 & 0.04 \\
WPAC-HF & 0.23 & 0.13 & $-0.46^{* *}$ & -0.13 & -0.03 \\
\hline
\end{tabular}

One, two and three stars indicate correlations significant at the $0.1,0.05$ and 0.01 two-sided levels respectively.

observed ones but with absolute values that are strongly underestimated (Table 3 ). The other AGCMs reproduce well the relationship with the southern and equatorial Atlantic but not the observed relationship with the central and eastern equatorial Pacific and western Indian Ocean (Table 3). Notice also that ECHAM 4 is very sensitive to the western Pacific SST but produces anomalies of opposite sign.

[12] Figure 3 displays running correlations obtained between the HF SRI and four HF SST indices. The observed linear relationship with NINO is quite accurately simulated by GISS (Figure 3a, cross) and ARPEGE (Figure 3a, circle) during the 1950-70s. Afterwards, modelled correlations
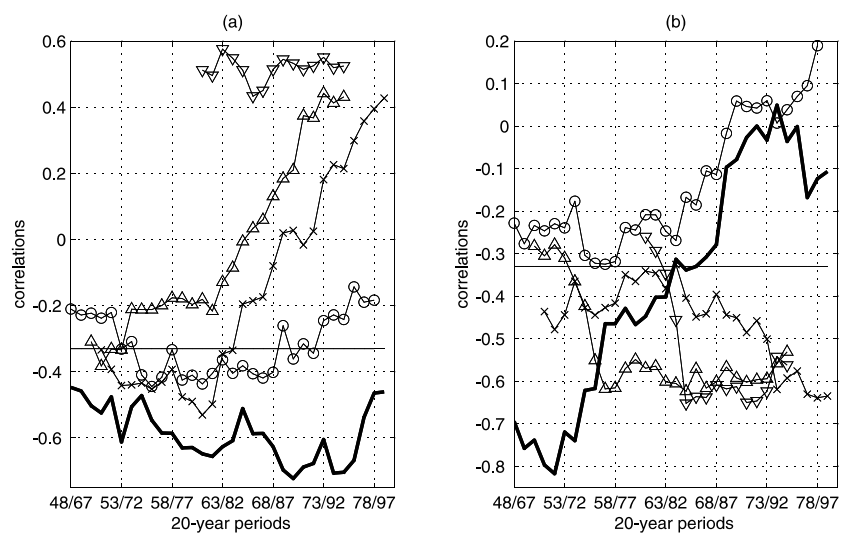

(c)
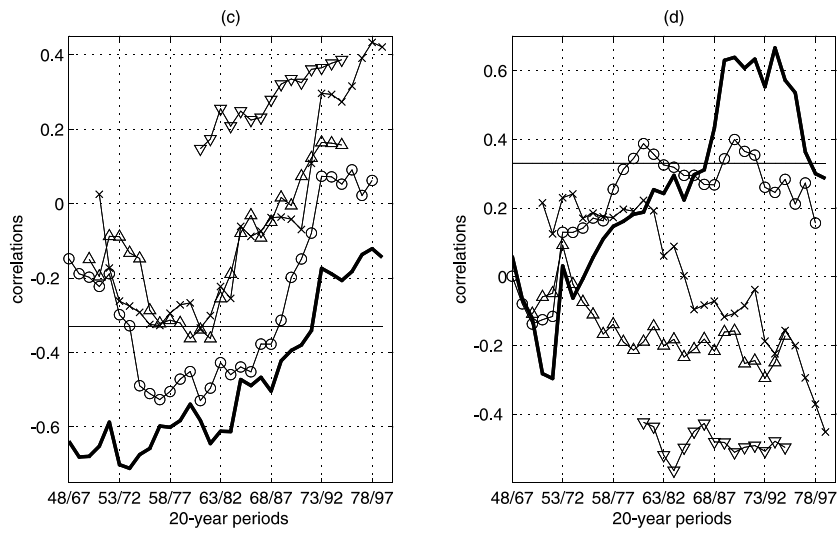

Figure 3. Running correlations on 20-year overlapping periods between HF observed (thick line) or simulated (thin line + circle: ARPEGE; upper triangle: ECHAM 3; lower triangle: ECHAM 4; cross: GISS) SRI and (a) HF-NINO; (b) HF-EAT; (c) HF-IND and (d) HF-WP (see text for SST index definitions). The straight line indicates the one-sided 0.1 level of significance (H1: correlation is negative for (a), (b) and (c) and positive for (d)). 
weaken whereas they strengthen in observations (Figure 3a, thick full line). When the dry period begins, the correlation between the observed SRI and EAT (Figure 3b, thick full line) tends to zero during the $1970-90 \mathrm{~s}$. Such an evolution is only simulated by ARPEGE (Figure 3b, circle) since the other AGCMs produce an evolution of the opposite sense. Considering the other SST forcings, especially WPAC, the AGCMs, except ARPEGE, simulate negative correlations during the dry period when significant positive ones are observed (Figure 3d).

\section{Concluding Remarks}

[13] The main low frequency (LF) signal of SRI variability, that is a change from wet (during the 1950-60s) to dry (during the 1970-90s) conditions, is well reproduced by the four AGCMs studied in this paper (Figure 1). This provides indirect evidence that recent abnormally dry rainy seasons are mainly due to low-frequency changes in SST forcing at large scale. Other results (Figure 2 and Table 2) clearly show that the HF signal is simulated less accurately. This can be partly attributed to the intrinsic variability of the simulated atmospheres: the SST-forced variance at HF timescales never exceeds $30 \%$ for the whole period, which defines an upper limit of model skill [Rowell, 1998]. The skill at HF timescales is also strongly model-dependent. We recall here that the HF skill of the West-African monsoon index for the same AGCMs (not shown) ranges from 0.5 to 0.7 during the 1963-1994 period. We could then hypothesize that the dynamical link between the regional monsoon and the SRI is underestimated in these AGCMs. Even if it is impossible to clearly explain the difference in skill obtained with each AGCM, the best skill at HF timescales is reached by the AGCM (i.e., ARPEGE) having the highest resolution, the most sophisticated land surface scheme (with GISS), but also having the largest ensemble (Table 1). The low resolution certainly introduces a misrepresentation of the rain events. Nevertheless, even ARPEGE appears to be under-sensitive to ENSO events. The SRI skill at HF timescales is lower over the recent dry period (1972-1990) than before, without however any systematic decrease of the SST-forced variance or of the coherency between AGCMs. Simulations do not capture the recent observed strengthening (weakening) teleconnection with the Pacific (Atlantic) SSTs. The decrease in skill could also partly be related to an increase of the continental surface forcing which is not prescribed in these experiments [Zeng et al., 1999; Zheng and Eltahir, 1998].

[14] Acknowledgments. We are grateful to Pierre Camberlin and the anonymous reviewer for their valuable comments. We thank Laurent Terray
(CERFACS) who gave us access to the ARPEGE runs and James Hansen (GISS) for his assistance with the GISS AGCM. We thank also Andrew Robertson (IRI) for his careful reading.

\section{References}

AMMA, On African Monsoon and its components, white book of the "African Monsoon Multidisciplinary Analyses project”, 53 pp., 2002.

Cassou, C., and L. Terray, Influence of tropical and extratropical SST on interannual atmospheric variability over the North Atlantic, J. Clim., 14, 4265-4280, 2001

Ebisuzaki, W., A method to estimate the statistical significance of a correlation when the data are serially correlated, J. Clim., 10, 2147-2153, 1997.

Folland, C. K., T. N. Palmer, and D. E. Parker, Sahel rainfall and worldwide sea temperatures, Nature, 320, 602-607, 1986.

Fontaine, B., and S. Janicot, Sea surface temperature fields associated with West African rainfall anomaly types, J. Clim., 9, 2935-2940, 1996.

Fontaine, B., S. Janicot, and V. Moron, Rainfall anomaly patterns and wind field signals over West Africa in August (1958-1989), J. Clim., 8, 1503 $1510,1995$.

Hansen, J., M. Sato, L. Nazarenko, R. Ruedy, A. Lacis, D. Koch, I. Tegen, T. Hall, D. Shindell, B. Santer, P. Stone, T. Novakov, L. Thomason, R. Wang, Y. Wang, D. Jacob, S. Hollandsworth, L. Bishop, J. Logan, A. Thompson, R. Stolarski, J. Lean, R. Wilson, S. Levitus, J. Antonov, N. Rayner, D. Parker, and J. Christy, Climate forcings in GISS simulations, J. Geophys. Res., D18, 4347, doi:10.1029/2001JD001143, 2002.

Hulme, M., Rainfall changes in Africa: 1931-60 to 1961-90, Int. J. Climatol., 12, 685-699, 1992.

Janicot, S., V. Moron, and B. Fontaine, Sahel droughts and ENSO dynamics, Geophys. Res. Lett., 23, 515-518, 1996.

Janicot, S., S. Trzaska, and I. Poccard, Summer Sahel-ENSO teleconnection and decadal time scale SST variations, Clim. Dyn., 18, 303-320, 2001.

Moron, V., A. Navarra, M. N. Ward, C. K. Folland, P. Friederichs, J. Polcher, and K. Maynard, Analysing and combining Atmospheric General Circulation Model simulations forced by prescribed SST. Part I: Tropical response, Annali di Geofisica, 44, 756-780, 2001.

Philippon, N., and B. Fontaine, A new statistical predictability scheme for July-September Sahel rainfall (1968-1994), Comptes-Rendus de l'Académie des Sciences, 329, 1-6, 1999.

Rowell, D. P., Assessing potential seasonal predictability with an ensemble of multidecadal GCM simulations, J. Clim., 11, 109-120, 1998.

Rowell, D. P., C. K. Folland, K. Maskell, and N. Ward, Variability of summer rainfall over tropical North Africa (1906-1992): Observations and modelling, Q. J. R. Meteorol. Soc., 113, 669-674, 1995.

Sperber, K. R., and T. N. Palmer, Interannual tropical rainfall variability in general circulation model simulations associated with the Atmospheric Model Intercomparison Project, J. Clim., 9, 2727-2750, 1996.

Sud, Y. C., and K. M. Lau, Comments on "Variability of summer rainfall over Tropical North Africa (1906-1992): Observations and modelling" by Rowell et al. (1995), Q. J. R. Meteorol. Soc., 22, $1001-$ $1006,1996$.

Ward, M. N., Diagnosis and short-lead time prediction of summer rainfall in tropical North Africa at interannual and multidecadal timescales, J. Clim., $11,3167-3191,1998$

Zeng, N. J., D. Neelin, K. M. Lau, and C. J. Tucker, Enhancement of interdecadal climate variability in the Sahel by vegetation interaction, Science, 286, 1537-1540, 1999.

Zheng, X., and E. A. B. Eltahir, The role of vegetation in the dynamics of West African monsoon, J. Clim., 11, 2078-2096, 1998.

B. Fontaine and N. Philippon, CRC, UMR 5080, Faculté Sciences Gabriel, 6 Boulevard Gabriel, 21000 Dijon, France.

V. Moron, CEREGE UMR 6635 CNRS, Europôle méditerranéen de l'Arbois, BP80, 13545 Aix en Provence, France. (moron@cerege.fr) 